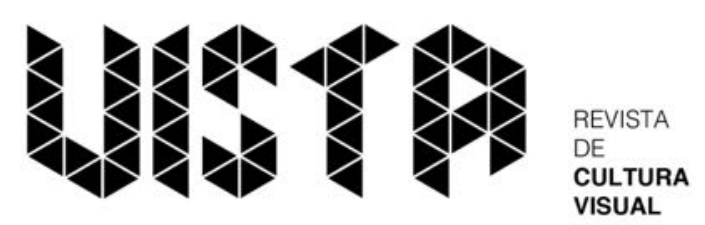

\title{
Etnografia de rua e arte urbana em Porto Alegre (RS,
}

Brasil)

Camila Braz da Silva, Cornelia Eckert, Diogo Dubiela, Fabrício Barreto, Felipe da Silva Rodrigues, Guillermo Gómez, Javier Calixto, José Luís Abalos Junior, Marielen Baldissera, Marina Bordin, Nicole Rigon, Roberta Simon, Rumi Kubo, Yuri Schönardie Rapkiewicz, Débora Wobeto, Leonardo Palhano, Luísa Dantas, Thayanne Tavares Freitas

\begin{abstract}
Resumo:
A prática da etnografia de rua implica um processo de pesquisa de campo em contextos urbanos para a captação de imagens fotográficas, videográficas e sonoras. Estas práticas etnográficas são desenvolvidas no âmbito de oficinas de antropologia visual com duração de um semestre ou um ano. Apresentamos o resultado da Oficina desenvolvida em 2017 pelos pesquisadores do Núcleo de Antropologia Visual (NAVISUAL) do Programa de Pós-Graduação em Antropologia Social da Universidade Federal do Rio Grande do Sul. Esta experiência de pesquisa foi finalizada com a montagem de uma exposição fotográfica no hall da Reitoria da UFRGS de novembro 2017 a janeiro 2018 e um filme intitulado Crônica com Tridente, artista urbano de Porto Alegre.
\end{abstract}

Palavras-chave: etnografia de rua, cidade, arte urbana, narrativa visual, imagem

\begin{abstract}
:
The practice of street ethnography implies a process of field research in urban contexts to capture photographic, videographic and sound images. These ethnographic practices are developed within the framework of visual anthropology workshops lasting a semester or a year. We present the results of the Workshop developed in 2017 by the researchers of the Visual Anthropology Nucleus (NAVISUAL) of the Graduate Program in Social Anthropology of the Federal University
\end{abstract}


of Rio Grande do Sul. This research experience was finalized with the assembly of a photographic exhibition in the hall of the Rectory of UFRGS from November 2017 to January 2018 and a movie entitled Chronicle with Tridente, street artist in Porto Alegre.

Keywords: street ethnography, city, urban art, visual narrative, image

\section{Introdução}

Esta narrativa visual resulta da pesquisa em antropologia visual desenvolvida em 2017 pela equipe de alunos e professores do Núcleo de Antropologia Visual (NAVISUAL) do Programa de Pós-Graduação em Antropologia Social da Universidade Federal do Rio Grande do Sul. A narrativa é uma síntese da exposição que teve por espaço o Saguão da Reitoria da UFRGS de novembro 2017 a janeiro 2018. Esta exposição intitulada Cartas aos Narradores Urbanos: etnografia de rua na Porto Alegre das intervenções artísticas foi organizada pela equipe do NAVISUAL e financiada pelo Departamento de Difusão Cultural da UFRGS, com a curadoria do técnico administrativo e antropólogo Rafael Derois Santos.

O NAVISUAL é um projeto de formação e de pesquisa em antropologia visual que completa 29 anos. A cada ano um novo desafio de estudo etnográfico com instrumentos audiovisuais e com formação teórico-conceitual no campo antropológico. A equipe reúne estudantes de graduação em Ciências Sociais, de mestrado e doutorado em Antropologia Social, pesquisadores e professores, em processos colaborativos e de partilha de conhecimentos. Os temas são variados com uma predominância na linha de pesquisa de antropologia urbana. Este foi o caso desta experiência contextualizada na cidade de Porto Alegre (RS, Brasil).

\section{Pesquisar com imagens na cidade}

Um projeto etnográfico se inicia pela escolha do tema e pela definição do campo conceitual, processos fundantes para o projeto de pesquisa de campo. A cada ano a escolha do tema é definida coletivamente. Com frequência, a coordenação do NAVISUAL propõe o desafio de um trabalho de campo coletivo na forma de etnografia de rua. Esta prática implica em estudo de autores em torno de um tema a ser abordado para a elaboração de uma narrativa com imagens em diferentes suportes (fotográfico, videográfico, sonoro e textual) com predomínio da captação fotográfica.

$\mathrm{Na}$ experiência vivida em 2017, nosso estudo teórico teve autores que refletem sobre o fenômeno urbano e a modernidade, por meio de experiências de deslocamento na 
cidade contemporânea. São autores que apostam na ação imaginante em seus escritos sobre a vida urbana e que reconhecem os habitantes da e na cidade como atores de uma história viva partilhada. No mundo urbano, do planejamento racional, reconhecemos as formas sensíveis que expressam artes de fazer e de saber e que fazem vibrar a memória coletiva do trajeto humano. Em 2017, o Navisual pode contar também com dois cursos de formação em antropologia visual com Ricardo Campos da Universidade Nova de Lisboa, Portugal, em abril 2017 e com Marian Moya da Universidad Nacional de San Martin, Argentina, em maio 2017.

As etnografias de rua são também precedidas de elaboração de roteiros para definir os territórios a serem percorridos, os equipamentos a serem utilizados e o guia de palavraschave e conceitos que orientam os pontos de observação da equipe. Uma pergunta nos orientou neste processo: que imagens nos habitam no cotidiano citadino, em nossas observações, nas nossas escutas, nos múltiplos processos de interação sejam estes para reconhecer identidades ou diferenças, semelhanças ou diversidades? Buscamos estas interpretações estudando nove intelectuais que para nós são colecionadores de imagens em suas obras na e da cidade contemporânea. Entendemos estes autores assim como nós, em nossa experiência etnográfica, como narradores urbanos. Estes autores adotam o processo de deslocamento na cidade como método de pesquisa e narram as cidades com a força das imagens, das alegorias e estéticas sensíveis. Walter Benjamin (1989), William Foote-Whyte (2005), Michel De Certeau (1996), Colette Pétonnet (2006), Ricardo Campos (2010), Hélio R. Silva (1993), Jose G. C. Magnani (1996), Cornelia Eckert \& Ana Luiza Rocha (2013) são os narradores. Fomos orientados pelas categorias de interpretação aludidas por estes autores nos textos lidos como um roteiro-guia de produção imagética.

A oficina de formação teve início em março de 2017 com a escolha de textos da obra destes autores que nos permitissem evocar a flânerie, a observação participante, a caminhada a passos perdidos, a etnografia de rua, a observação flutuante e as interlocuções com os habitués das ruas. Estas práticas de reconhecer e narrar as complexidades da vida cotidiana na cidade figuram os tipos urbanos, as multiplicidades das paisagens citadinas, em especial aquela marcada por gestos e rastros de habitantes que expressam seus afetos ou seus medos, seus protestos ou suas resistências às lógicas normativas e determinantes institucionais que atravessam as subjetividades e sufocam as liberdades criativas da pessoa moderna.

Estas formas de narrar inspiram a equipe à experiência do deslocamento em diversos percursos e circuitos realizados coletivamente em diferentes territorialidades, quatro para sermos mais precisos. Em todo o processo a elaboração das constelações de imagens considera a reflexão do campo conceitual estudado. 
A aventura nos bairros da cidade e as etnografias nas ruas, ocorreram na companhia de artistas especializados em arte urbana ou curadores de arte na cidade a partir da promoção de política públicas que analisamos como formas de democratização ao direito a cidade. Suas narrativas ao longo das caminhadas misturam experiências biográficas, reconhecimento de redes de artistas, grupos de luta e solidariedade, equipes rivais e disputas de lugares, políticas públicas ou denuncias da inoperância do Estado em face da promoção de vida pública, falam das margens, das resistências, dos projetos e frustrações.

\section{Saída de campo no bairro Cidade Baixa: muros, esquinas e moradias}

A primeira saída a campo em abril de 2017, foi realizada no bairro Cidade Baixa, em Porto Alegre, e teve o acompanhamento de Ricardo Campos (Cicsnova, FCSH Univ. Nova de Lisboa). Contamos com a presença de treze pesquisadores, devidamente equipados com câmeras de fotografia, vídeo e gravadores de som. Uma artista também nos acompanhou neste percurso, Adauany Zimovsky, estudante de história da arte e pesquisadora do tema da pichação. Nosso principal mediador foi o artista visual Tridente, que propôs o itinerário da saída junto com a equipe. Tridente foi um interlocutor importante em todo o percurso, relatando processos, contextos e contando histórias dos grafites e seus autores. A equipe se movimentava em torno de Tridente para escutar suas orientações e narrativas, captadas em vídeo e gravador.

A caminhada da equipe pelo bairro registrou diversos momentos do cotidiano. Os pesquisadores focaram seu ponto de observação nas intervenções artísticas urbanas. As paredes deste lugar estão marcadas por stencil, pichações e grafites.

O muro do Colégio La Salle Pão dos Pobres é um exemplo da convivência de manifestações legais e ilegais que marcam a paisagem visual do bairro Cidade Baixa. Andando pelo "Beco do Agachados", rua que se localiza atrás de uma das principais passagens do bairro boêmio, encontramos várias edificações completamente marcadas pelas intervenções de pichadores. Durante nossas caminhadas pela cidade, foram várias as indagações de habitantes sobre nosso interesse. Não raro, nestas ocasiões, os moradores demonstram a tensão cotidiana do convívio com as práticas de intervenção na cidade. Captamos imagens de alguns destes interlocutores explicitando nossa motivação e anotando sua direção de modo a manter contato para posteriores convites e consentimentos. 


\section{Saída a campo no bairro Floresta: centros culturais, ateliês e grafites legalizados}

No percurso pensado para o Quarto Distrito/ bairro Floresta, buscamos seguir os caminhos de um projeto de grafite legalizado, já existente no bairro: o ZIS Grafite. Realizamos um circuito visitando os grandes murais orientados por um aplicativo que baixamos em um celular. Esta orientação foi dada para nós pela arquiteta Clara Freund, curadora do projeto ZIS Grafite, projeto este que contou com financiamento municipal para elaboração de um percurso turístico a cargo do grafite". Através de uma mensagem no Whatsapp, Clara informou-nos: "Amigos, vocês podem fazer a caminhada sozinhos; a ideia é que todos assim o façam. Em cada intervenção há uma placa de identificação com um chip ligado a um QR Code, que se pode acompanhar no celular caminhando pelo bairro".

A tecnologia que chegou aos percursos da arte urbana em Porto Alegre foi compartilhada por nós, caminhantes conectados, orientados por um open access nas esquinas do chamado Distrito Criativo. Durante este percurso, percebemos a vinculação do projeto com a instauração de centros culturais e de economia criativa. A pintura dos murais do ZIS Grafite havia ocorrido no mês anterior ao da nossa caminhada e os próprios habitantes do bairro estavam reconhecendo as intervenções. Um dos pontos do ZIS Grafite é um centro cultural nominado de Vila Flores, antiga moradia de operários do bairro industrial, que hoje funciona como um centro cultural. Caminhando pelas ruas Câncio Gomes e São Carlos, visitamos ateliês de artistas e pontos de cultura como o hostel da rua São Carlos que tem suas paredes grafitadas por artistas e um piano à disposição para os conhecedores da arte de tocar.

\section{Saída a campo na Avenida Voluntários da Pátria, bairro Navegantes: ruínas, escolas e periferias}

A caminhada realizada na Avenida Voluntários da Pátria, que atravessa diversos bairros, foi marcada pela observação de muitas ruínas provenientes de um processo de desindustrialização. O bairro Navegantes, por onde nos deslocamos, tem uma paisagem urbana distinta do bairro Floresta. Realizamos muitas imagens desta estética de degradação e com a presença de muitas intervenções ilegais nos antigos prédios industriais, alguns abandonados outros em funcionamento. Nesta saída, fomos acompanhados pelo artista André Venzon que, além de ajudar a programar os percursos 
possíveis das caminhadas na cidade em um momento inicial, esteve presente neste trajeto.

André é um artista engajado no movimento cultural da cidade, em prol de artistas urbanos. Nos guiou tanto por territórios com as características de crise e abandono quanto em zonas marcadas por projetos de revitalização, uma das características marcantes do Quarto Distrito, mais recentemente conhecido por Distrito Criativo, dado os inúmeros investimentos de economia criativa no local. Por ali convivem empreendimentos comerciais, centros culturais e muitos ateliês de artistas. Nas ruas também encontramos catadores de lixo, moradores sem teto, prostitutas, carroceiros, entre outros personagens da vida ordinária. Durante nosso percurso, visitamos a escola Camila de Furtado, que se localiza nas imediações do Centro Cultural Vila Flores e da Vila Santa Teresinha. Fomos recebidos pela diretora que permitiu que fotografássemos os trabalhos de alunos expostos por ocasião das comemorações do dia das mães. Filmamos seu relato a respeito dos esforços da escola para atender a população de alunos carentes da região.

Assim, tivemos acesso a outra visão do que é o cotidiano de uma região marcada pela resiliência dos habitantes, em especial dos professores da escola que entrevistamos. Estes enfrentam a falta de segurança e o medo pela vulnerabilidade das crianças em face da violência na cidade. No fim deste trajeto, Venzon abriu-nos a porta do seu ateliê; ali conversamos sobre o fenômeno da vinda de vários artistas, inclusive daqueles que têm na cidade espaços de intervenção, como o Quarto Distrito.

\section{Saída a campo no Centro Histórico: rastros de projetos artísticos e a política de revitalização do centro}

Em nosso último percurso, produzimos imagens do centro histórico da cidade. Partimos do Mercado Público e percorremos a Avenida Mauá, região do Cais do Porto caracterizada pela presença de um muro construído nos anos 60 para proteção contra enchentes. O muro é colorido por inúmeros grafites, o que o torna uma galeria a céu aberto de artistas de Porto Alegre. Percorrer as ruas centrais é testemunhar a presença marcante das intervenções do artista urbano Xadalu e sua vinculação com a temática indígena. Outros artistas, como Toniolo, também se fazem notar.

Seguimos para um território conhecido por reunir prédios de funções políticas do Estado Rio Grande do Sul. O local é conhecido como "Alto da Bronze”, próximo a uma escadaria que divide a parte alta da parte baixa da cidade (centro). Testemunhamos o projeto "Arte 
Urbana a Céu Aberto" da artista Ana Paula Monjeló, que nos acompanhou nessa caminhada pela velha região da cidade. Esta galeria é abrigada em uma casa em ruínas com riscos de desabamento. Entrar neste espaço implicou em um consentimento tanto pela artista que nos acompanhou como pela líder da associação de horta comunitária situada no local.

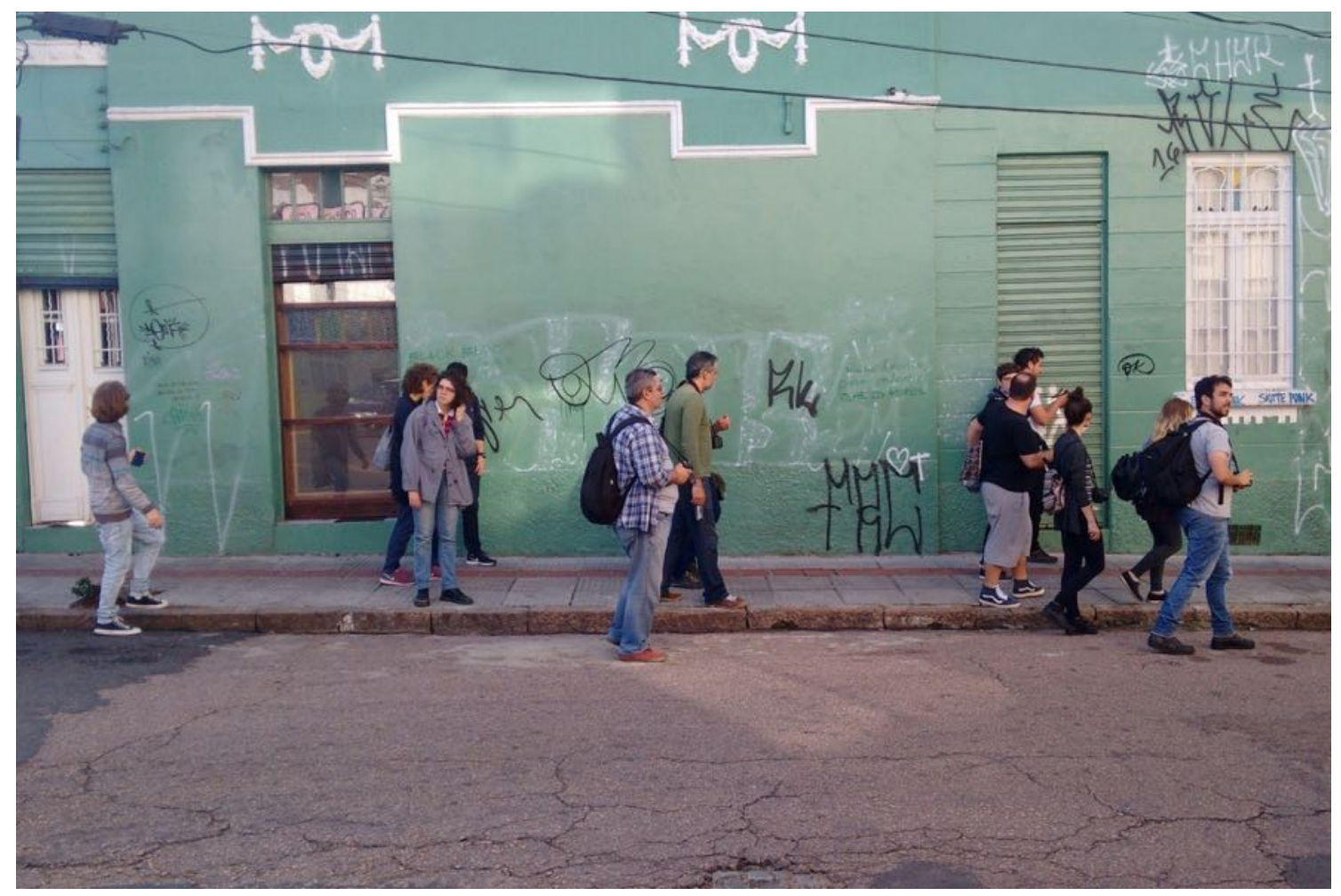



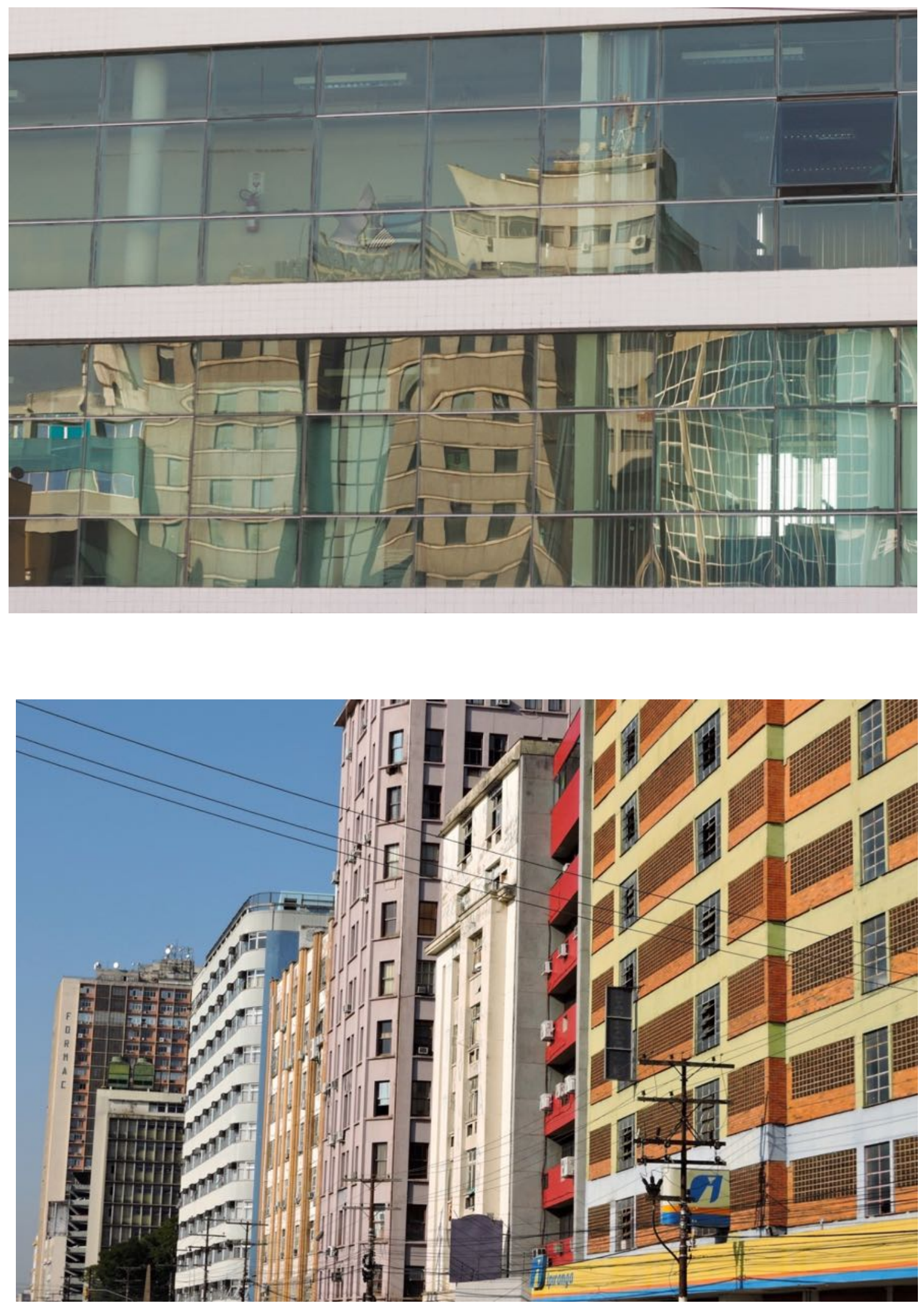

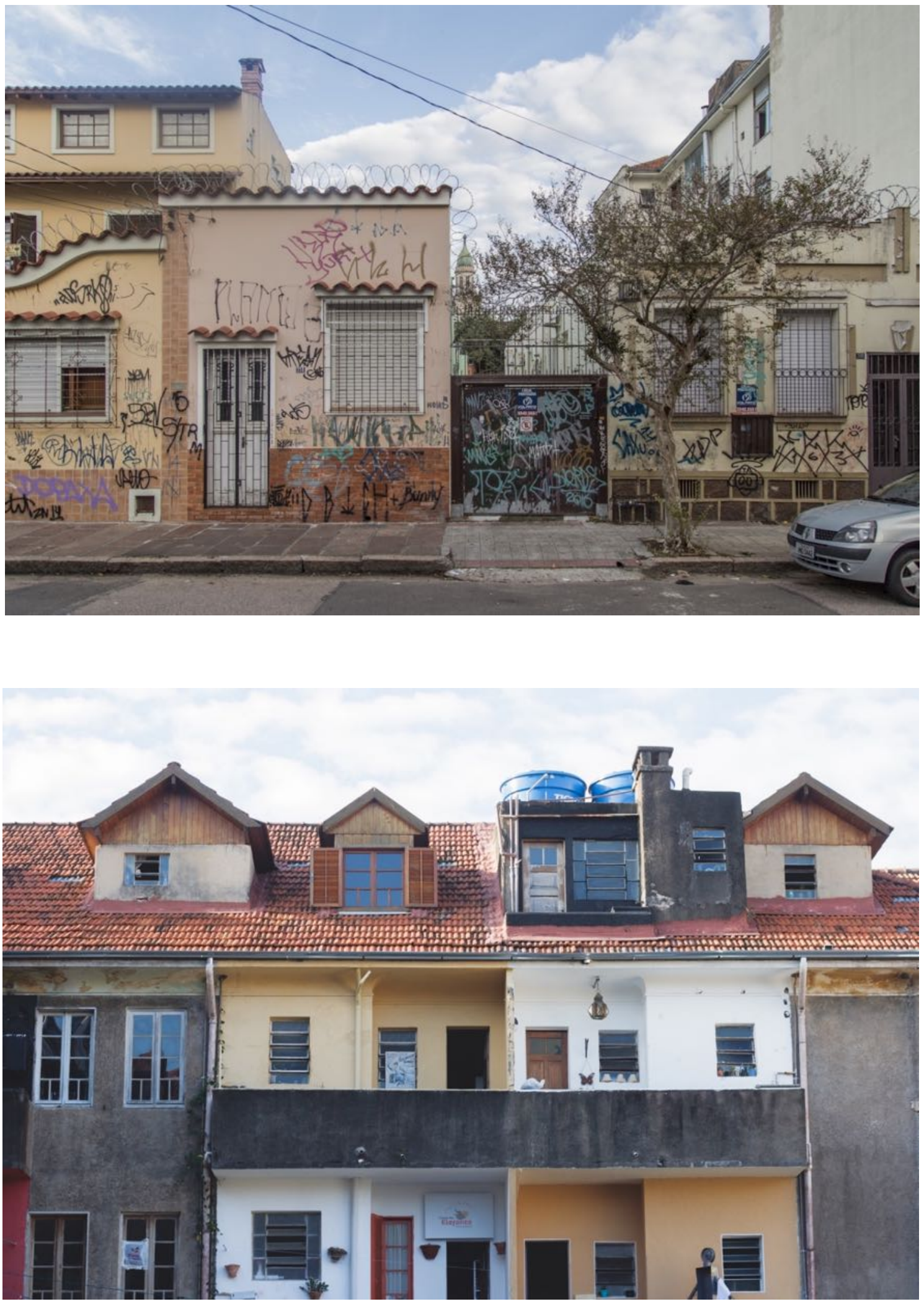

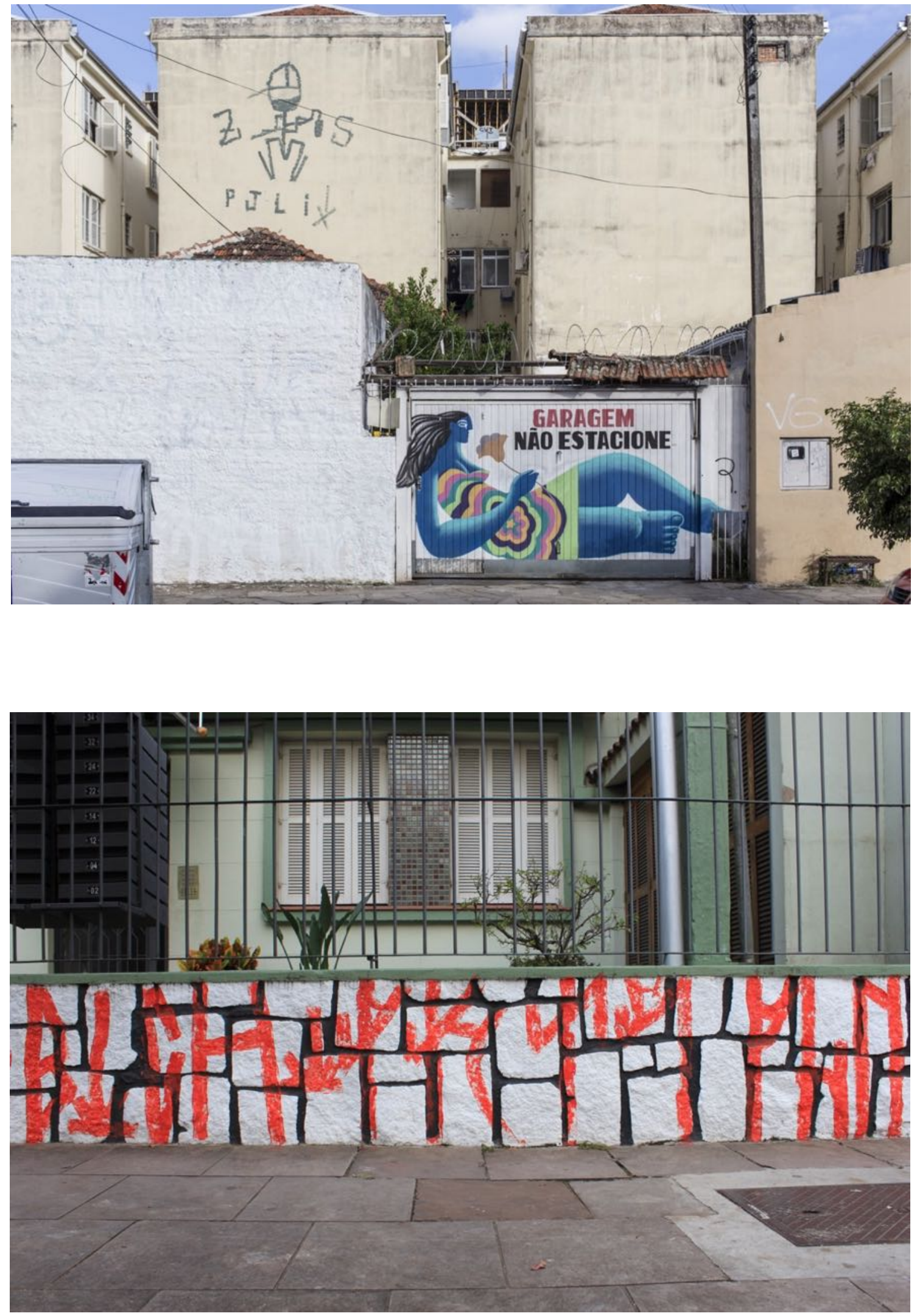

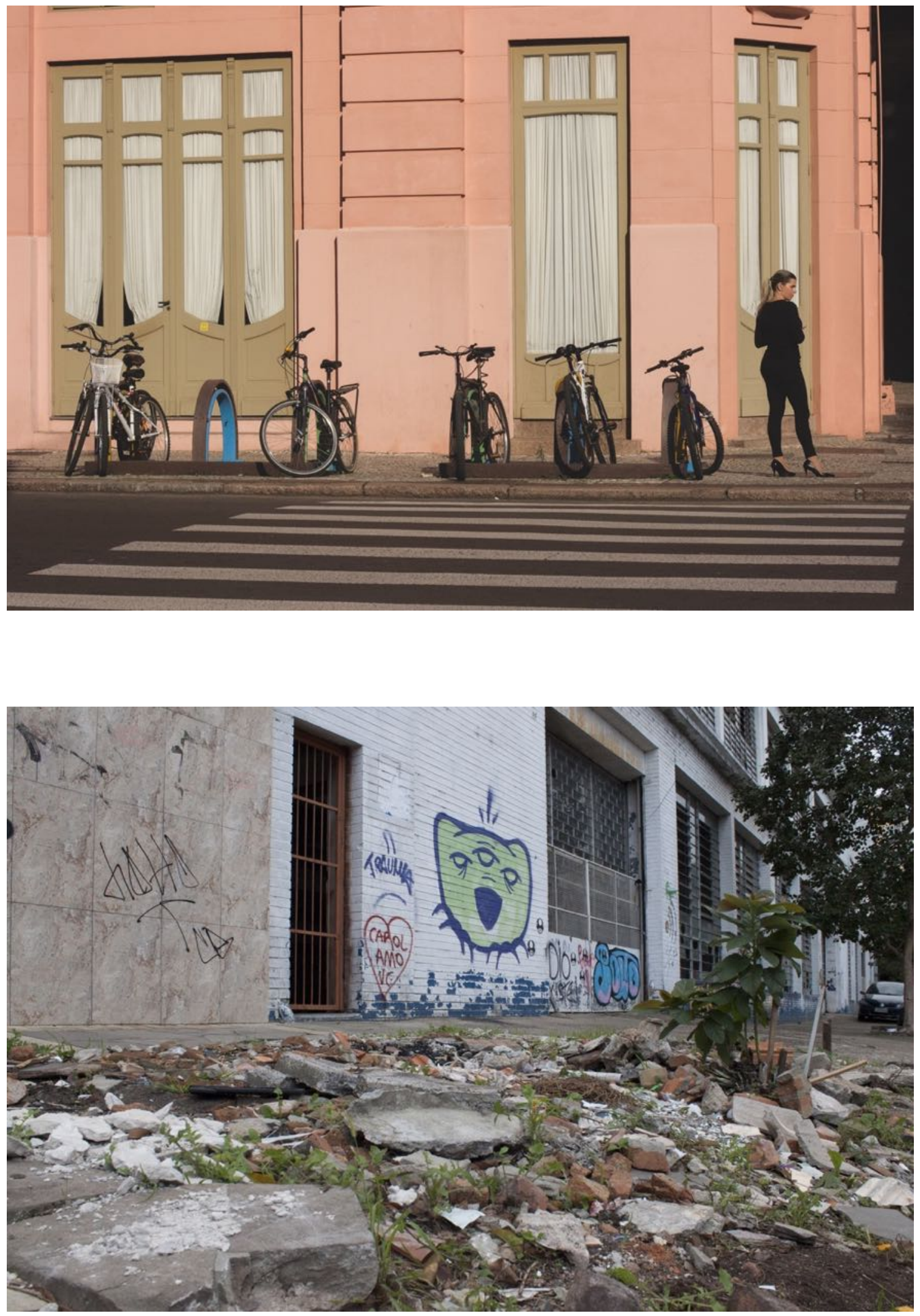

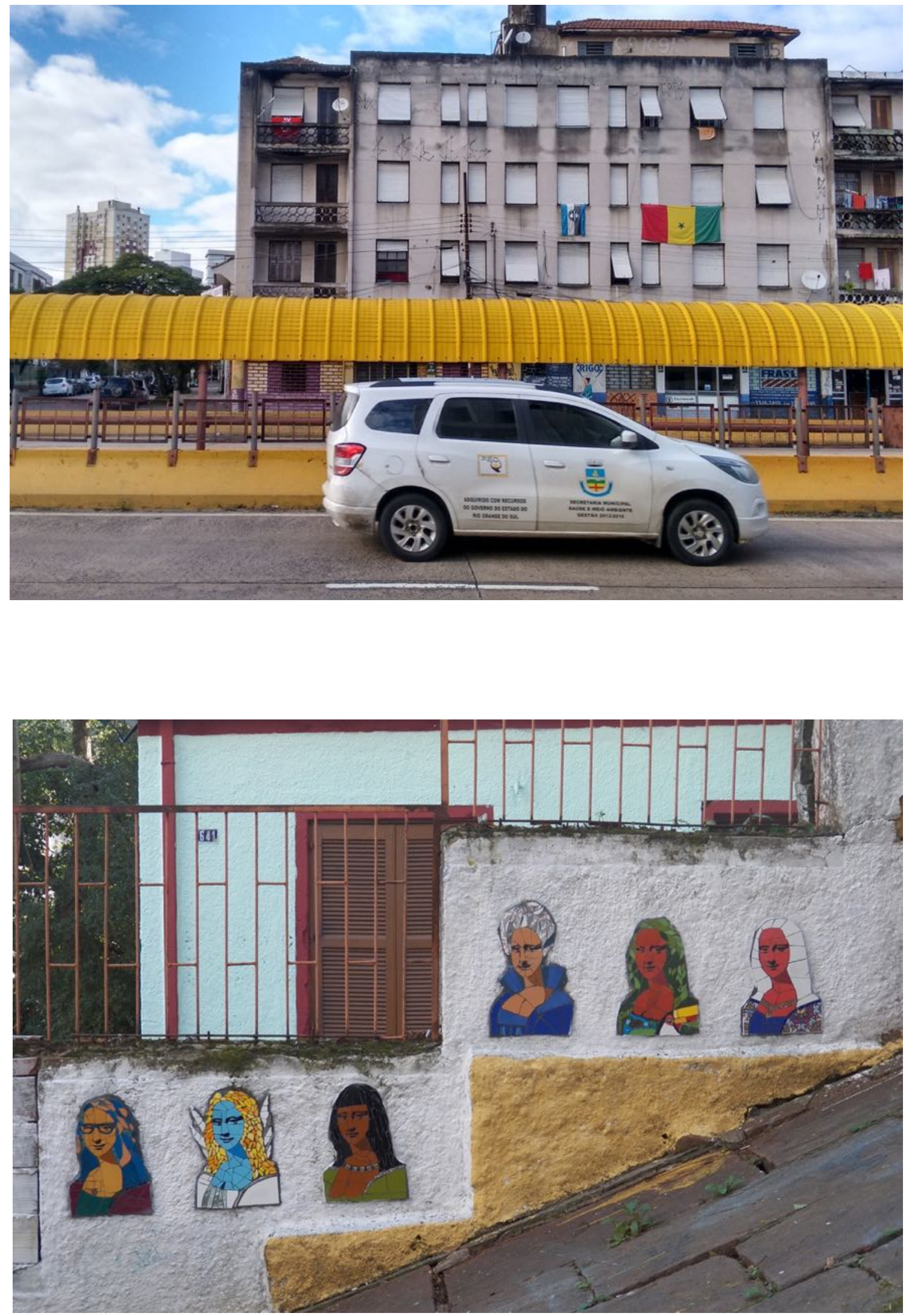

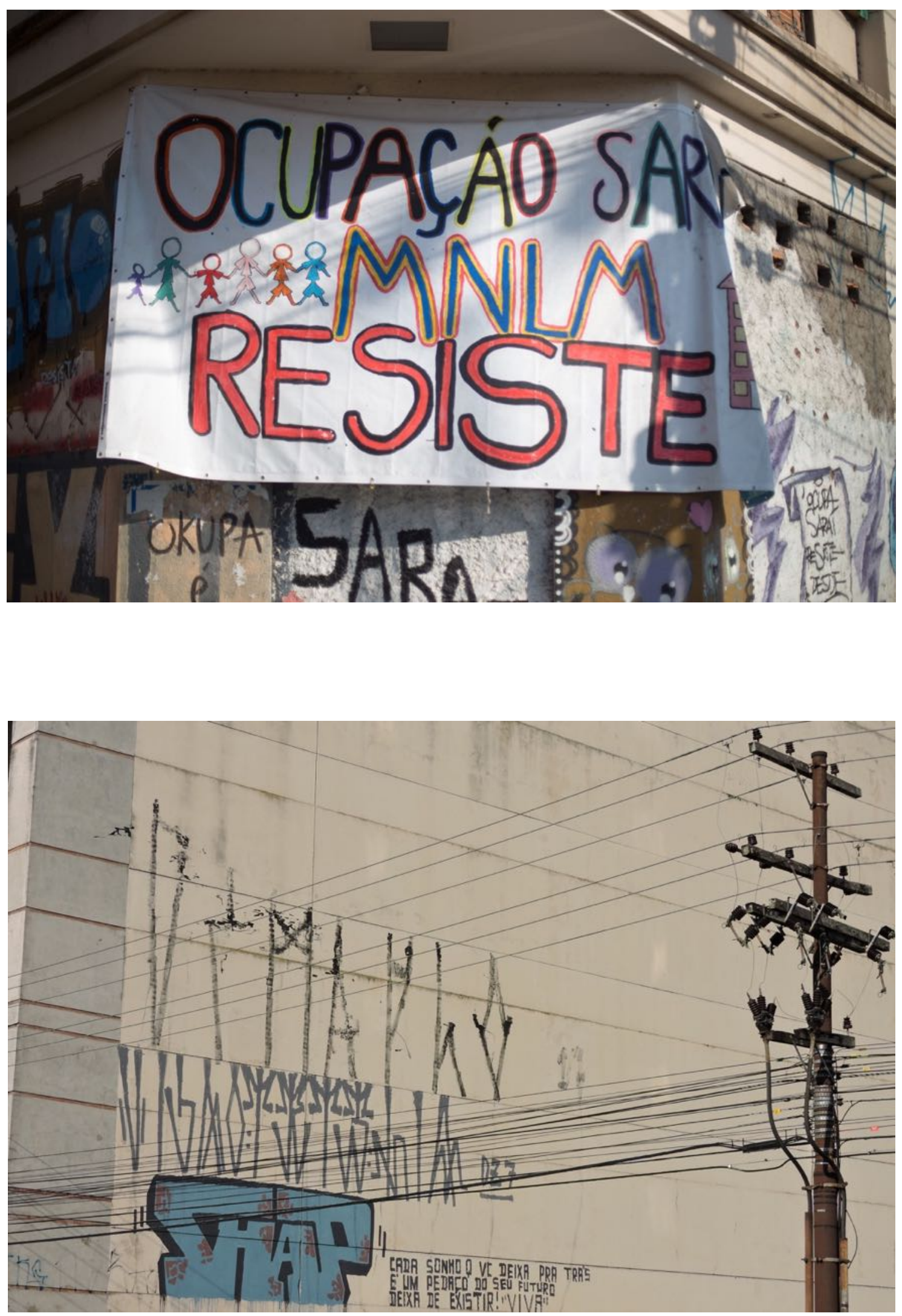

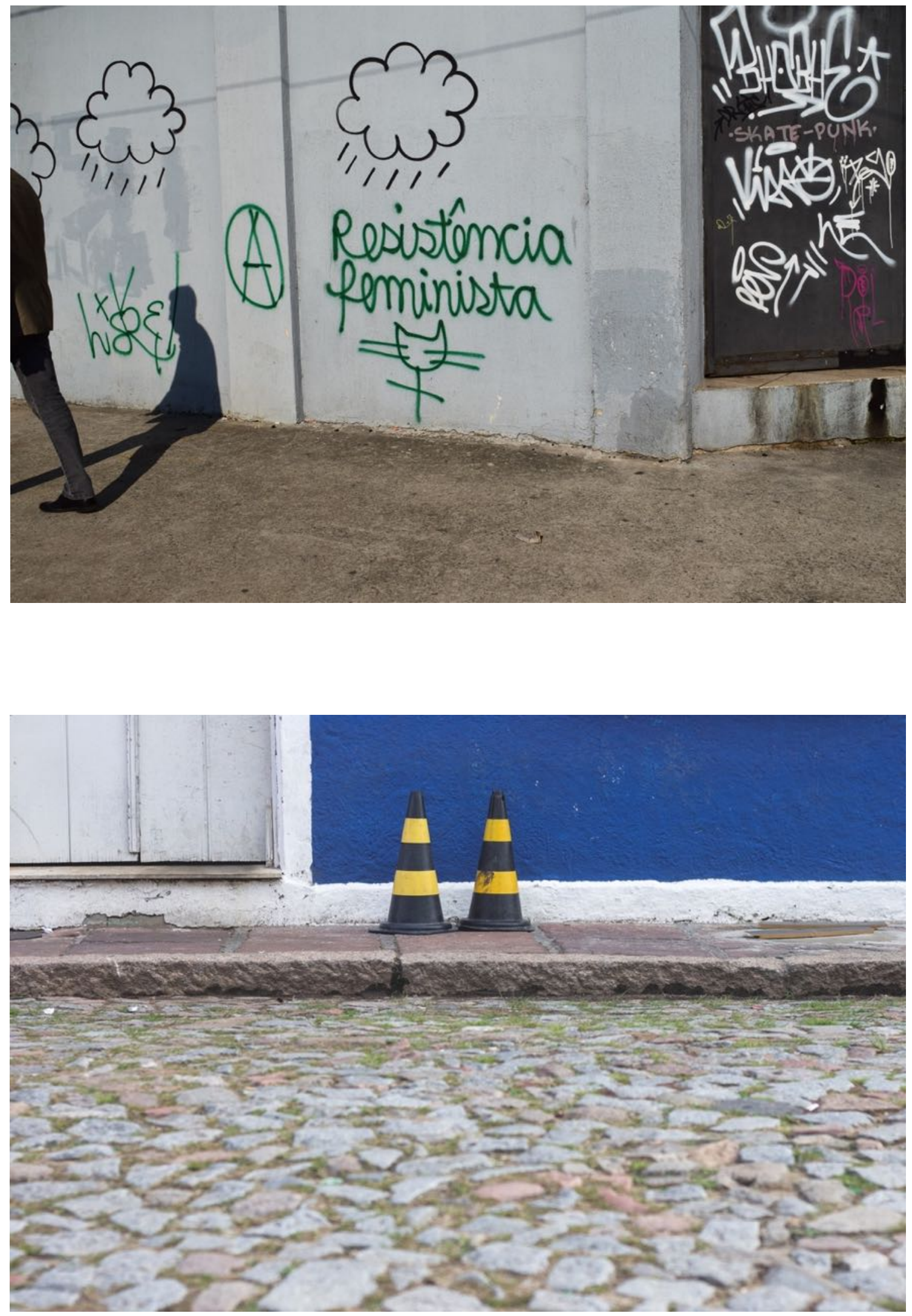

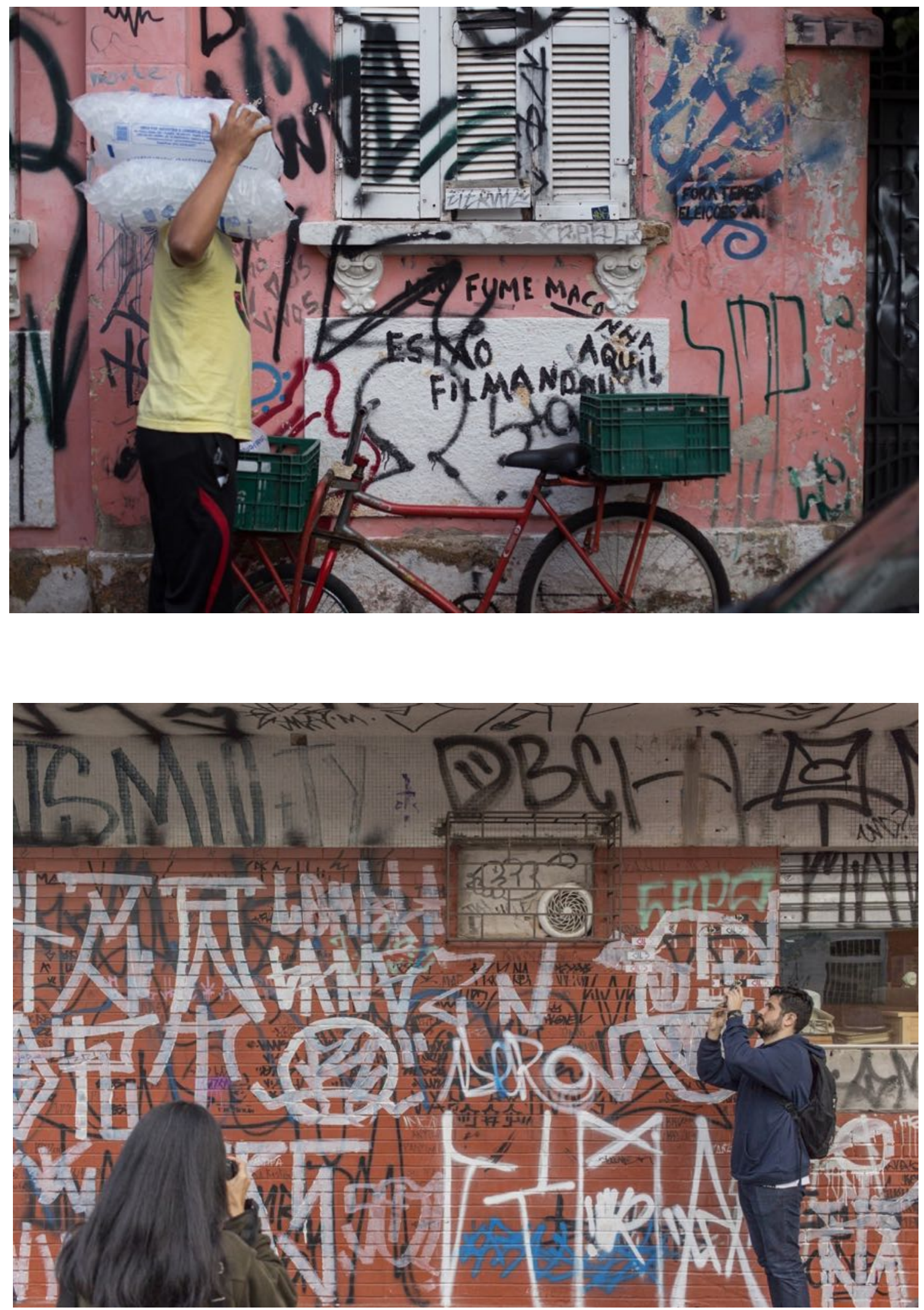

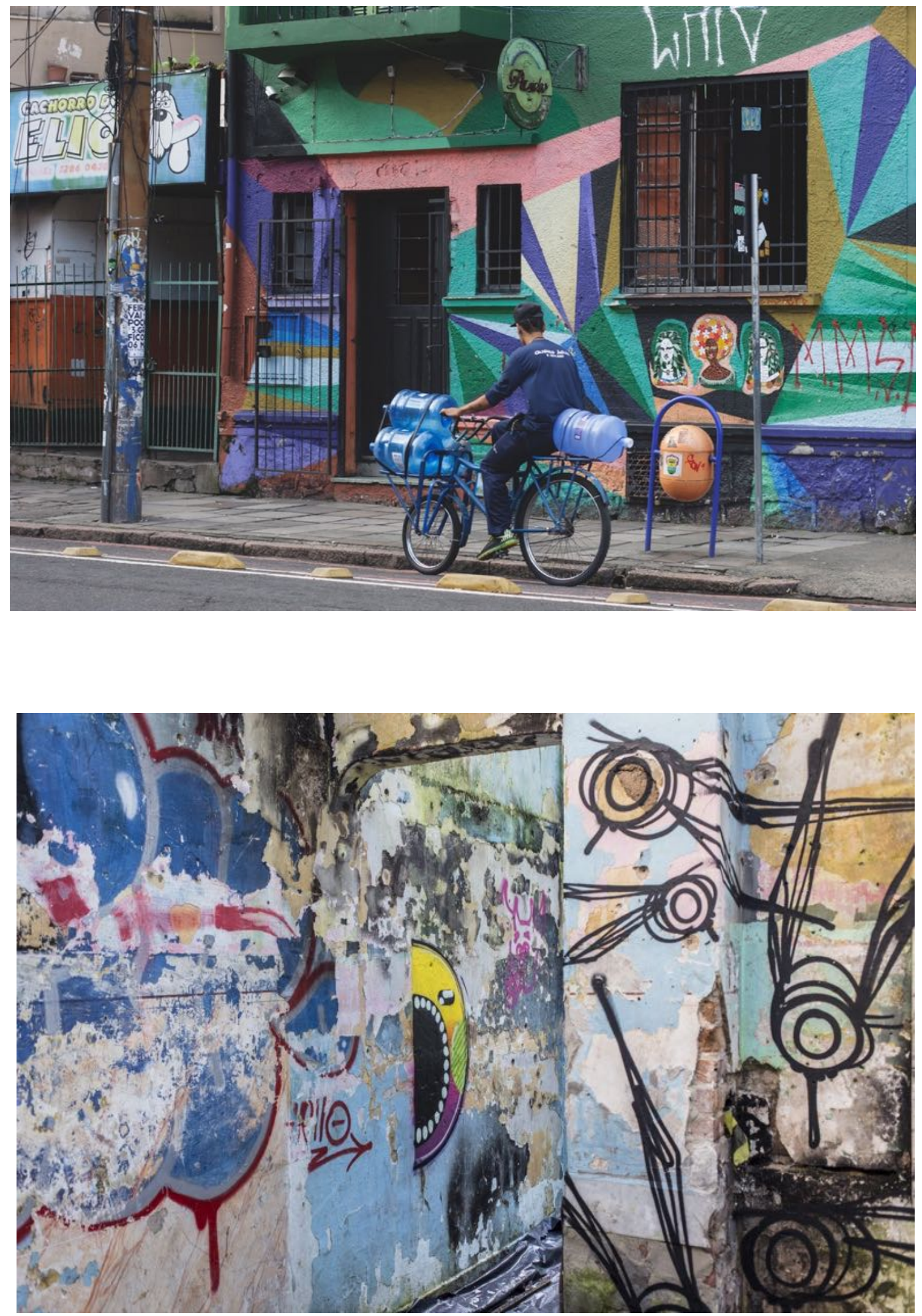

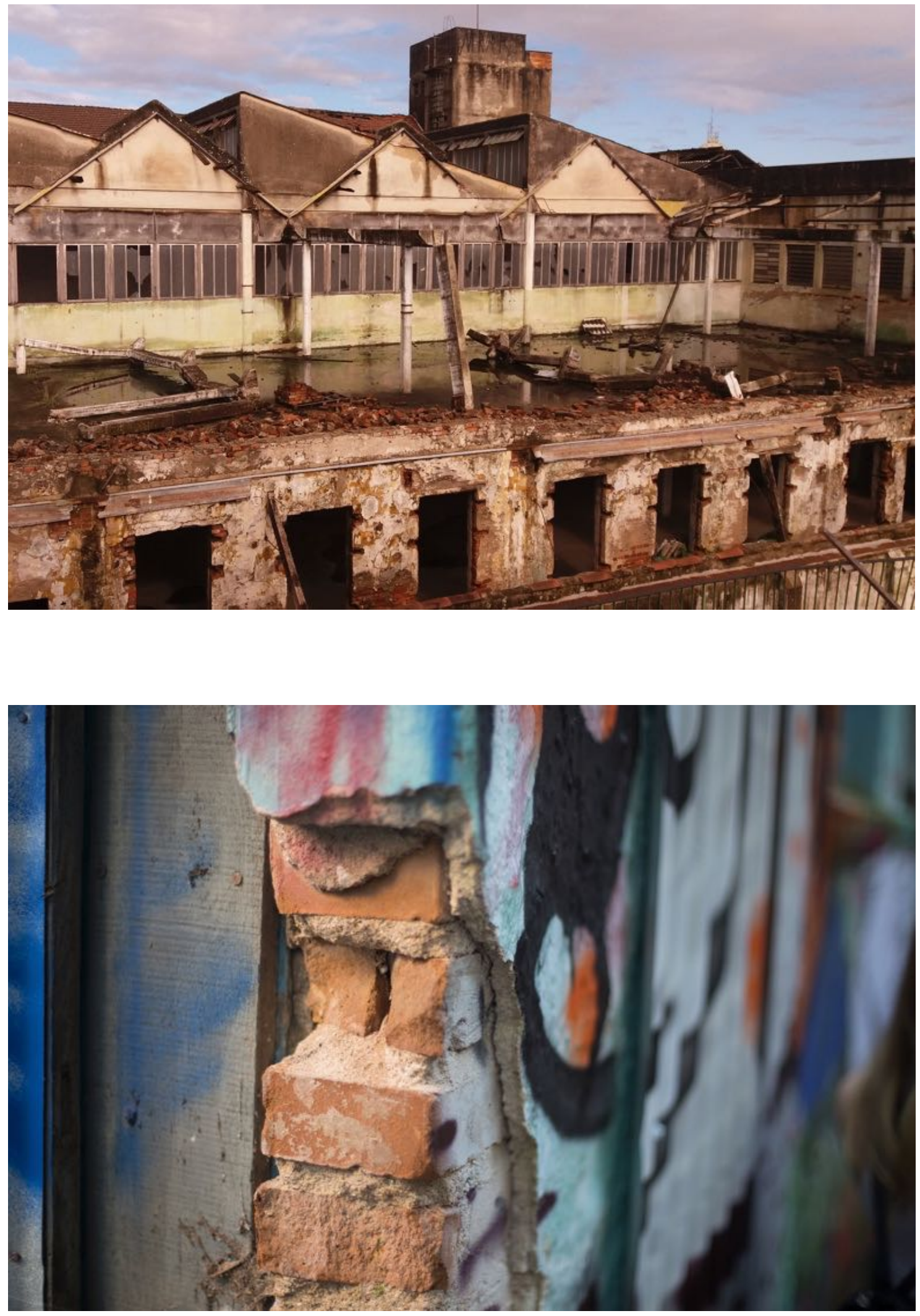

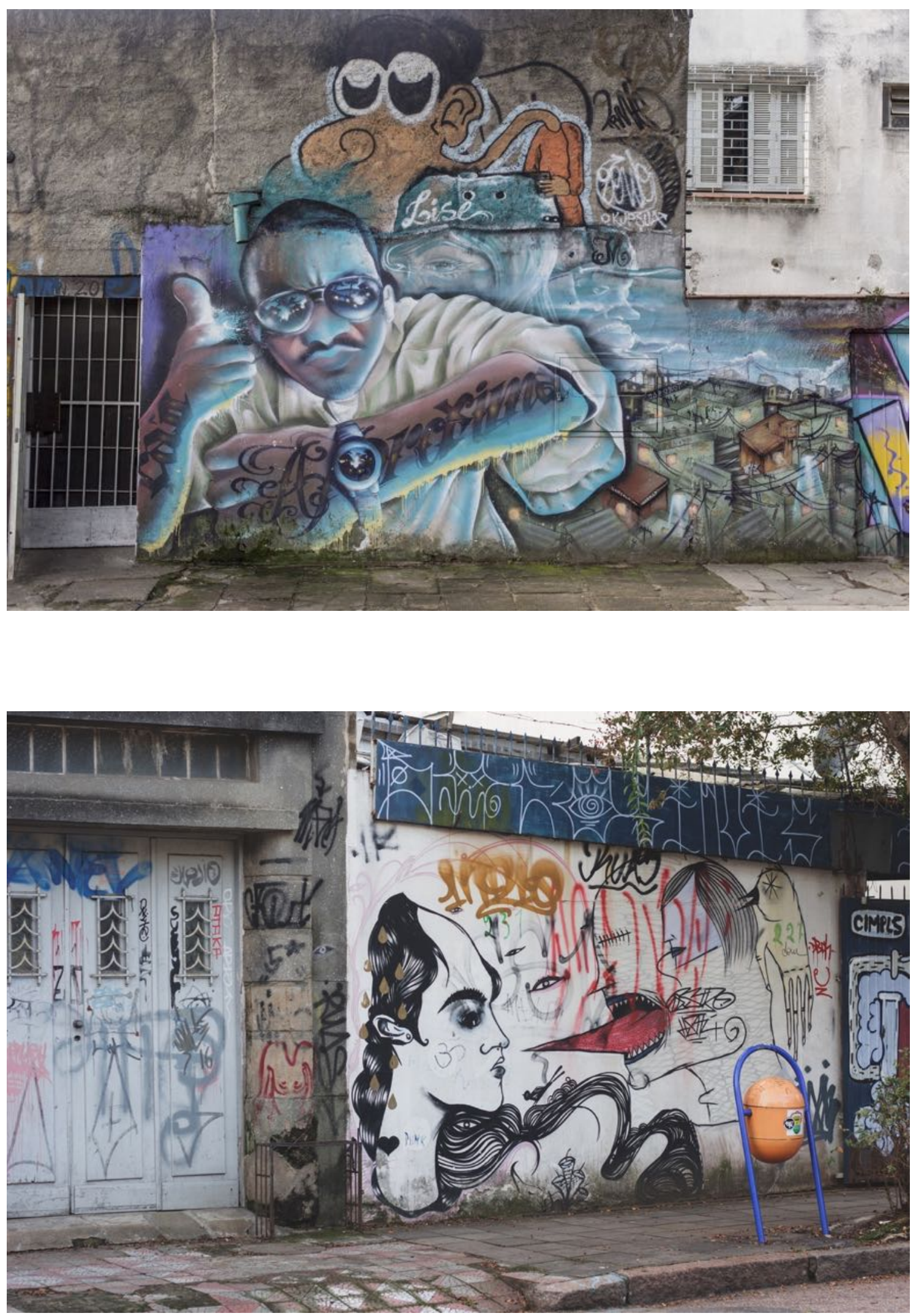

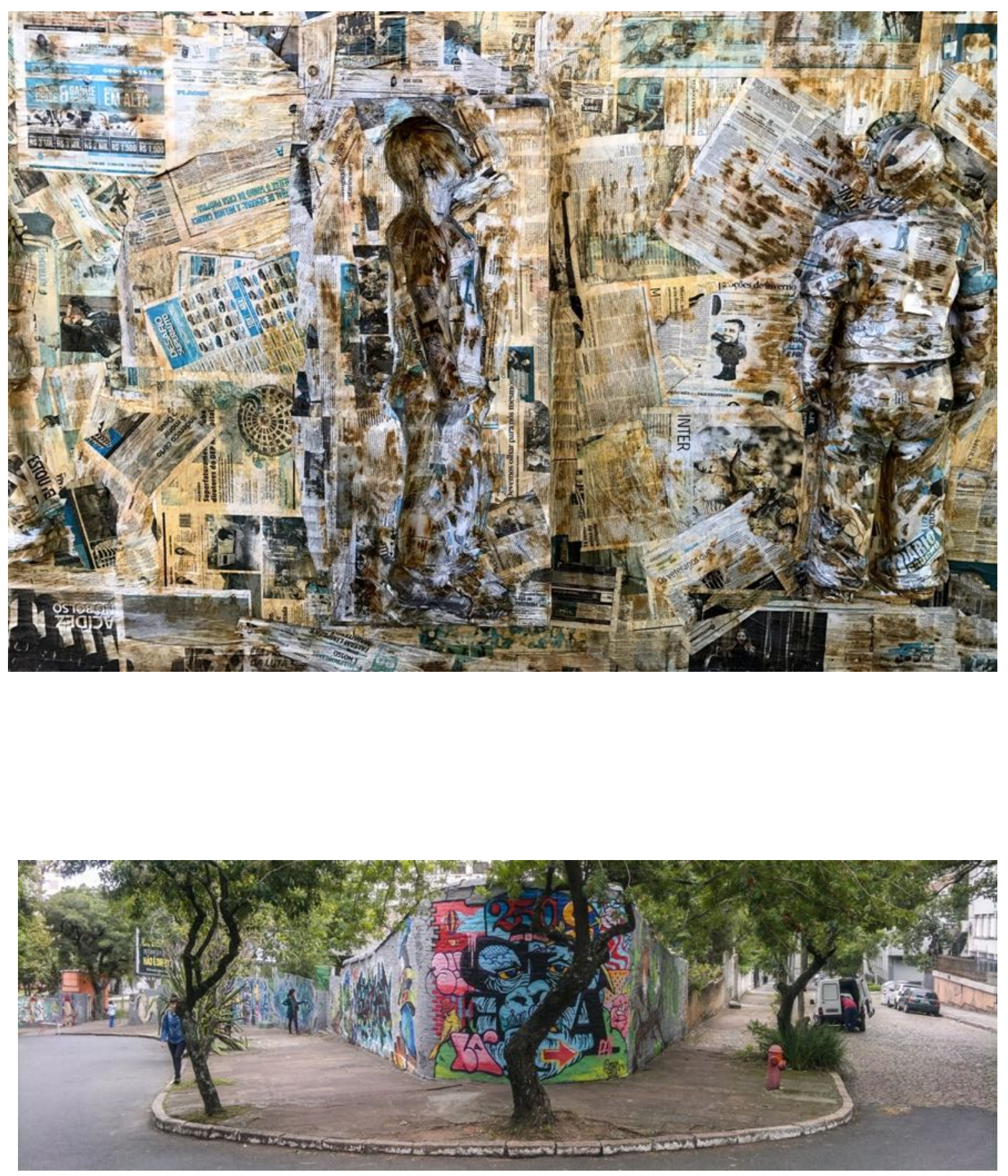


\section{Referências bibliográficas}

Benjamin, W. (1989). O flâneur. In Walter Benjamin: Obras escolhidas. São Paulo: Editora Brasiliense.

Campos, R. (2010). Porque pintamos a cidade? Uma abordagem etnográfica ao graffiti urbano. Lisboa: Fim de Século.

De Certeau, M. (1996). A invenção do cotidiano. Artes de fazer. Petrópolis: Vozes.

Eckert, C. \& Rocha, A. L. C. (2013). Etnografia de rua. Porto Alegre: Editora da UFRGS.

Magnani, J. G. C. (1996). Na metrópole: textos de antropologia urbana. São Paulo: EDUSP/FAPESP.

Pétonnet, C. (2008). A observação flutuante: exemplo de um cemitério parisiense. Antropolítica, n. 25, 99-111.

Silva, H. R. S. (1993). Travesti, a Invenção do Feminino. Rio de Janeiro: RelumeDumará.

Whyte, W. F. (2005). Sociedade de esquina. Rio de Janeiro: Jorge Zahar Editor. 